\title{
Botulinum toxin treatment of severe dysphagia following brainstem stroke
}

\author{
Domenico De Grandis ${ }^{1}$, Sofia Faletti ${ }^{1}$, Francesco Pirali ${ }^{2}$, Gianna Santus ${ }^{1}$ \\ ${ }^{1}$ Department of Rehabilitation, Fondazione Poliambulanza, Brescia, Italy \\ ${ }^{2}$ Local Health Unit, Cremona, Italy \\ Email: gianna.santus@poliambulanza.it
}

Received 30 August 2013; revised 29 September 2013; accepted 6 October 2013

Copyright (C) 2013 Domenico De Grandis et al. This is an open access article distributed under the Creative Commons Attribution License, which permits unrestricted use, distribution, and reproduction in any medium, provided the original work is properly cited.

\begin{abstract}
Objective: To evaluate botulinum toxin treatment of hyperactive upper esophageal sphincter after firsttime brainstem stroke. Design: A retrospective study. Subjects: Twelve patients with long standing dysphagia after brainstem vascular injury admitted to the rehabilitation department of a medical centre. Methods: All patients underwent clinical examination, videofluoroscopic study of swallowing and electromyography. Botulinum toxin was injected percutaneously under electromyographic guide. Outcomes were measured after two weeks and through a long follow up programme, which ranged from two to ten years. Results: A total of $75 \%$ of patients (9 of 12) had favourable outcomes. Two patients showed long lasting functional benefits after only one botulinum toxin injection, while seven patients required further treatments to maintain an adequate oral intake. In seven cases it was possible to remove percutaneous endoscopic gastrostomy. No relevant complications were observed. Conclusion: Botulinum toxin can improve severe dysphagia with elective hyperactivity of the upper esophageal sphincter in patients with or without unilateral paresis of the inferior constrictor muscle and in absence of a nuclear involvement of the IXth and Xth cranial nerves. The outcome could be unsatisfactory in the cases of oral phase involvement, bilateral lesion of the inferior constrictor muscle and when there is velopharyngeal insufficiency.
\end{abstract}

Keywords: Deglutition Disorders; Brainstem Stroke; Upper Esophageal Sphincter; Rehabilitation; Botulinum Toxins; Electromyography; Gastrostomy

\section{INTRODUCTION}

Dysphagia is a severe and debilitating disorder often consequence of brainstem stroke [1]. It is estimated that swallowing is affected up to $70 \%$ of cases in the acute stroke phase [2]. Among patients with a medullary infarction, dysphagia is more common if the lesion is at the upper or middle and dorsolateral medullary level [1] and persistent deglutition disorders are often associated with lower brainstem lesions [3-5]. The medullary stroke syndromes can have various swallowing impairments. In such cases, dysphagia can be characterized by pharyngeal dysmotility, velopharyngeal insufficiency, pharyngeal asymmetry and incomplete relaxation of the upper esophagus sphincter (UES) that can lead to retention of food materials in the pharynx and aspiration into the larynx and trachea. An impaired opening of the UES is particularly related to the dorsolateral level of brainstem lesion [1]. After the acute brainstem stroke phase, dysphagia tends to recover, therefore, there are only a few patients with persistent and severe dysphagia and not all of them have hyperactivity of UES. Further, swallowing disorders caused by brainstem stroke show different clinical and videofluoroscopic characteristics in respect to hemispheric lesions [6].

Botulinum toxin (BT) has widely been used for treating spasticity or other movement disorders and it has also been proposed for dysphagia. Several researches revealed that BT is useful to heal cricopharyngeal dysphagia consequent to heterogeneous neurological or head and neck pathologies [7] using different treatment techniques and outcome measures. Few studies concerned dysphagia after brainstem stroke and each research considered only a small number of patients.

The goal of the present study was to assess the effectiveness of BT treatments on a fairly numerous series of subjects with persistent cricopharyngeal dysphagia consequent to brainstem stroke. The study examined the effect of BT after percutaneus injection under electromyographic guide, the duration of BT action, the number 
of treatments needed after the first one, the outcomes after each treatment and then in the follow up. A further purpose was to better characterize the clinical and instrumental features (extension of neurological deficits, cranial nerves involvement, swallowing and feeding impairments) of patients who may benefit from these treatments.

\section{METHODS}

\subsection{Subjects}

Twelve outpatients with a diagnosis of persistent dysphagia after brainstem stroke were enrolled in the study. They had been referred to a neurologist in a Rehabilitation Department from 2002 to 2010.

Participant selection criteria included: primary diagnosis of brainstem stroke with magnetic resonance imaging (MRI), confirmation of swallowing disorder with impaired UES opening at the videofluoscopic study of swallowing (VFSS), duration of dysphagia at least four months from stroke onset and medical stability at the time of the study. Exclusion criteria included: a further neurological disease other than stroke, upper gastrointestinal disease and cognitive impairments.

The general characteristics of the patients are summarized in Table 1. They were seven males and five females, with a mean age of 56.6 years (range $36-80$ years). In 11 cases, dysphagia was caused by an ischemic injury, while one had an haemorrhagic stroke. The locations and extent of lesions were analysed by brain mag- netic resonance imaging (MRI). Each subject had alert mental status. They had been suffering from dysphagia for a period ranging from four months to four years (mean 7.6 months). Non-oral feeding was required for 11 patients and was provided by percutaneous endoscopic gastrostomy (PEG), while one patient was able to feed orally with texture restrictions. Five of the patients had undergone tracheostomy.

All the patients had undergone a tailored swallowing rehabilitation treatment with specific strategies and techniques, including oral motor therapy, tactile-thermal oropharyngeal stimulations, active exercise to strengthen the swallowing musculature and oral manipulation, postural techniques, dietary adjustments, voluntary manoeuvres and breathing coordination.

\subsection{Procedures}

\subsubsection{Baseline Assessment}

Each patient's swallowing was assessed through clinical and instrumental examinations (Table 2). A clinical assessment of dysphagia was performed with a Bedside Swallowing Examination (BSE), in compliance with Logemann's test procedure [8,9] that included the examination of cranial nerves, oral motility, laryngeal elevation, voluntary cough and a swallowing test. Patients were given three portions of $10 \mathrm{ml}$ of crushed ice, water, fruit mousse, juice and a biscuit. Cervical auscultation was adopted simultaneously with the swallowing test, placing the stethoscope at the lateral border of the tra-

Table 1. General characteristics of patients (F indicates female; $M$, male; $Y$, yes; N, no).

\begin{tabular}{|c|c|c|c|c|c|c|c|}
\hline Subjects: & age (yr), sex & Diagnosis (stroke) & Tracheostomy & PEG & Months & PAS & Prosiegel score \\
\hline 1 & $39, \mathrm{~F}$ & Bulbar haemorrhagic & $\mathrm{Y}$ & $\mathrm{Y}$ & 11 & 7 & 6 \\
\hline 2 & $78, \mathrm{M}$ & Bulbar & $\mathrm{Y}$ & $\mathrm{Y}$ & 12 & 4 & 6 \\
\hline 3 & $79, \mathrm{M}$ & Bulbar, left pontine & $\mathrm{N}$ & $\mathrm{Y}$ & 4 & 7 & 5 \\
\hline 4 & $46, \mathrm{M}$ & Bulbar & $\mathrm{N}$ & $\mathrm{Y}$ & 5 & 5 & 5 \\
\hline 5 & $62, \mathrm{M}$ & Bulbar, left cerebellar & $\mathrm{Y}$ & $\mathrm{Y}$ & 24 & 7 & 5 \\
\hline 6 & $56, \mathrm{M}$ & Bulbar & $\mathrm{Y}$ & $\mathrm{Y}$ & 4 & 7 & 6 \\
\hline 7 & $80, \mathrm{~F}$ & Bulbar & $\mathrm{N}$ & $\mathrm{Y}$ & 12 & 4 & 5 \\
\hline 8 & $48, \mathrm{~F}$ & Bulbar, dorsal pontine & $\mathrm{N}$ & $\mathrm{Y}$ & 4 & 4 & 3 \\
\hline 9 & $50, \mathrm{~F}$ & Brainstem & $\mathrm{N}$ & $\mathrm{N}$ & 3 & 4 & 6 \\
\hline 10 & $67, \mathrm{M}$ & Nucleus tractus solitarii & $\mathrm{N}$ & $\mathrm{Y}$ & 2 & 7 & 6 \\
\hline 11 & $36, \mathrm{~F}$ & Brainstem (vertebral artery dissection) & Y & $\mathrm{Y}$ & 2 & 7 & 5 \\
\hline 12 & $39, \mathrm{M}$ & Bulbar, dorsal pontine & $\mathrm{N}$ & $\mathrm{Y}$ & 7 & 5 & 5 \\
\hline \multirow[t]{2}{*}{$\mathrm{N}(12)$} & & & 5 & 11 & & & \\
\hline & Mean 56.6 & & & & 7.6 & 6.2 & \\
\hline
\end{tabular}


Table 2. Clinical and instrumental dysphagia pre-BT evaluation ( ${ }^{*} 9$ patients only were able to complete the swallowing test).

\begin{tabular}{cc}
\hline Pre-BT evaluation & N (12) \\
\hline 1) BSE & \\
Cranial nerve deficits & 6 \\
Oral phase deficits & 6 \\
Cough deficits & 10 \\
Hypersialorrhea & 6 \\
Aspiration signs & 7 \\
Language deficits & $9 / 9^{*}$ \\
Fatigue & $9 / 9^{*}$ \\
Multiple swallowings & \\
2) VFS & 12 \\
UES incomplete opening & 12 \\
Pharyngeal residue & 7 \\
Aspiration & \\
3) EMG & 12 \\
Cricopharingeal hyperactivity &
\end{tabular}

chea immediately inferior to the cricoid cartilage. It was assessed each consistency for evidence of: coughing or chocking, normal or abnormal sounds, multiple swallows for bolus and dump post-swallowing sounds. The examination was performed by medical doctors. Three patients were fed exclusively by tube with no oral intake, so in these cases BSE was conducted without the swallowing test. The severity of dysphagia was classified according to the Prosiegel scale [10], that graduates swallowing impairment and functional features in six levels: level 1 (oral swallowing with postural strategies or compensative technique), level 2 (oral swallowing with texture limitation), level 3 (texture limitation and postural strategies or compensative technique), level 4 (partial oral swallowing), level 5 (partial oral swallowing with functional compensations), level 6 (severe dysphagia requiring nonoral feeding).

Videofluoroscopic study of swallowing was performed on all the patients. Three different food consistencies of standardized bolus size were used: thin liquid (equivalent to milk), semisolid (equivalent to jelly), and solid (dry toast coated in barium). Not all the patients were given all the consistencies depending on the severity of dysphagia. All patients had impaired opening of the UES. Other common findings included: large vallecular and pyriform sinuses residue after swallowing in all the patients and aspiration from pyriform sinuses' residue caused by pharyngeal weakness in seven patients. Fur- ther, patients presented multiple swallowing to clear boluses from the pharynx to the esophagus. The features displayed by VFSS were used to graduate dysphagia severity using the Rosenback [11] penetration-aspiration scale (PAS). This is an 8 point scale that measures the depth of airway invasion and whether material entering the airway is expelled (level 1: material does not enter the airway; level 2: material enters the airway, remains above the vocal folds, and is ejected from the airway; level 3: material enters the airway, remains above the vocal folds, and is not ejected from the airway; level 4: material enters the airway, contacts the vocal folds, and is ejected from the airway; level 5: material enters the airway, contacts the vocal folds, and is not ejected from the airway; level 6 material enters the airway, passes below the vocal folds, and is ejected into the larynx or out of the airway; level 7: material enters the airway, passes below the vocal folds, and is not ejected from the trachea despite effort; level 8: material enters the airway, passes below the vocal folds, and no effort is made to eject).

Electromyography (EMG) was performed to detect the cricopharyngeal muscle involvement in dysphagia. Voluntary swallowing was electromyographycally characterized by a pause in the cricopharyngeal muscle, corresponding to UES relaxation. It was considered inadequate when there was a persistent EMG activity during swallowing.

\subsubsection{Botulinum Toxin Injection}

The subjects gave their informed consent to the treatment before starting. Within the consent paper there was a list of potential adverse effects which included: laryngeal muscle paralysis, dysphonia, cervical muscle weakness, dysphagia worsening, local haematoma and pain in the injection site.

Botulinum toxin type A (Botox, Allergan, Irvine, California, USA or Xeomin, Merz Pharmaceticals, Frankfurt am Main, Germany) was percoutaneusly injected into the cricopharingeal muscle under EMG control using a teflon-coated needle. For each patient, a variable dose of 15 - 30 units of botulinum toxin ( $2 \mathrm{ml}$ dilution, $0.9 \%$ saline) was injected into one or both side of the cricopharyngeal muscle. The needle was inserted percutaneously $1.5 \mathrm{~cm}$ lateral to the palpable inferior border of the cricoid cartilage. Then it was advanced in a postero-medial direction following the contour of the cricoid cartilage. Patients were asked to vocalize in order to exclude the possibility of placement in the intrinsic laryngeal musculature and to tense their neck and to tilt their head to prevent needle placement in the strap or paraspinal muscles. Needle placement in the UES was confirmed by muscle activity as indicated by an active EMG signal at rest. 


\subsubsection{Follow up}

Functional outcomes were measured by rating the swallowing impairments and the nutritional intake two weeks after BT injection. Further, patients underwent a long follow up, time ranging from two to ten years, during which it was periodically assessed the evolution and changes of dysphagia about every 4 months.

An optimal outcome was defined as a significant clinical improvement, as measured by the Prosiegel scale, of at least three levels, with an augmentation of the oral intake, the possibility to swallow more consistencies, the removal of the enteral tube and weight gain. A good outcome was considered where a patient could resume oral feeding but had to observe texture restrictions and a postural strategy and maintain a partial PEG feeding. Patients who didn't have a good outcome underwent a test to value BT efficacy through the injection of BT into an indicator muscle, the extensor digitorum brevis (EDB). It was measured the compound muscle action potentials elicited by electrical nerve stimulation of the peroneal nerve before and after BT injection [12].

\subsubsection{Data Analysis}

Data were registered using a computer recording system, that is Microsoft Access software for Windows. A statistical analysis was performed using the STATA package (Stata Statistical Software: Release 12.0 College Station. TX: Stata Corporation). It was adopted $\chi^{2}$-test and Fisher-test for category variables and the Student T-test for paired data for normally distributed variables. All the tests were two-tailed and performed using a 0.05 threshold for rejecting the null hypothesis.

\section{RESULTS}

Table 3 shows the efficacy of BT treatment in each case. An optimal outcome was reached in seven cases with a significant improvement in the swallowing function and the removal of PEG feeding. Two patients reported a good outcome as characterized by improved swallowing for liquid and/or solids, but they still required postural strategies and texture restrictions. On the other hand three patients did not have a clinical improvement and dysphagia remained unchanged after BT treatment.

Among the group with an optimal or good outcome, two cases needed only one BT injection to solve dysphagia; gastrostomy was removed and there was a full recovery of swallowing. The benefits of BT therapy were stable after returning to oral feeding.

Seven patients underwent a further BT treatment during the follow up. The injection was repeated periodically every three to four months according to the response of each patient. Five patients had a good recovery after several treatments (from 2 to 5), with tube feeding being discontinued. Table 4 shows the clinical features of
Table 3. Efficacy of BT injection for each patient.

\begin{tabular}{cccccc}
\hline Subject & $\begin{array}{c}\text { Post-BT } \\
\text { Prosiegel }\end{array}$ & Efficacy & $\begin{array}{c}\text { Feeding } \\
\text { tube } \\
\text { removal }\end{array}$ & $\begin{array}{c}\text { Number of } \\
\text { treatments }\end{array}$ & $\begin{array}{c}\text { Long term } \\
\text { follow up } \\
\text { (years) }\end{array}$ \\
\hline 1 & 6 & no & & 1 & 2 \\
2 & 1 & good & $\mathrm{x}$ & $>4$ & 6 \\
3 & 2 & good & & $>4$ & 10 \\
4 & 1 & good & $\mathrm{x}$ & 1 & 3 \\
5 & 1 & good & $\mathrm{x}$ & $>4$ & 4 \\
6 & 6 & no & & 3 & 2 \\
7 & 5 & no & & 3 & 2 \\
8 & 1 & good & & 1 & 6 \\
9 & 1 & good & $\mathrm{x}$ & 4 & 2 \\
10 & 1 & good & $\mathrm{x}$ & 1 & 10 \\
11 & 1 & good & $\mathrm{x}$ & $>4$ & 2 \\
12 & 1 & good & $\mathrm{x}$ & 1 & 2 \\
Mean & 2.25 & & & & \\
\hline -value & 0.0003 & & & & \\
\hline
\end{tabular}

Table 4. Change in modes of feeding after BT injection.

\begin{tabular}{cccc}
\hline Feeding & Non oral & oral & Mixed \\
\hline Pre-BT & 8 & 3 & 1 \\
Post-BT & 2 & 7 & 3 \\
\hline
\end{tabular}

patients who had a good outcome, compared with those who did not. We observed that the three patients that did not experience a significant improvement of dysphagia had aspiration and cranial nerve deficits before BT treatment.

Table 5 shows the modes of feeding after BT injection. After BT treatments, seven patients could receive predominantly oral feeding, three patients received partial oral feeding and maintained PEG, and only two patients still required strictly non-oral feeding.

As complications, one patient reported a local transient pain, a second one presented a transient worsening of the dysphonia after one BT injection and a third one experienced a transient worsening of gastro-esophageal night reflux disease.

\section{DISCUSSION}

The use of botulinum toxin to treat dysphagia in a successful and efficient way has been widely documented in literature $[13,14]$. However, past studies included patients with heterogeneous clinical characteristics, such as disorders of the oral phase, and with a variable involvement of the central or peripheral nervous system. Further, 
they often covered both chronic progressive disorders and post-acute cases that could have a chance of spontaneous recovery.

It was carried out a review of literature focusing on dysphagia consequent to non progressive neurological pathologies, with a defined brain-stem site lesion [1520].

Six studies reported detailed information regarding 23 patients giving full data on clinical diagnosis, severity, injection dose, efficacy and duration of response to BT intervention (Table 6).

16 of the 23 were treated with BT injection under endoscopic guidance, while the remaining 7 were treated under EMG guidance. Moreover, marked improvements in swallowing and nutrition were found in 19 out of 23 patients $(82 \%)$ after BT injection. Most of them were initially fed by gastrostomy or nasogastric tube. In 9 cases it was possible to remove tube feeding (39\%).

Table 5. Comparison of features of patients with good versus poor outcome after BT.

\begin{tabular}{cccc}
\hline & $\begin{array}{c}\text { Good outcome } \\
(\mathrm{N} 9)\end{array}$ & $\begin{array}{c}\text { Poor outcome } \\
(\mathrm{N} 3)\end{array}$ & p-value \\
\hline Age (mean) & 56 & 58 & 0.8 \\
Sex (M/F) & $6 / 3$ & $1 / 2$ & \\
$\begin{array}{c}\text { Duration of dysphagia, } \\
\text { month (mean) }\end{array}$ & 19.1 & 23.6 & 0.7 \\
$\begin{array}{c}\text { Dysphagia score (mean) } \\
\text { PAS score (mean) }\end{array}$ & 5.1 & 5.7 & 0.4 \\
Aspiration (N) & 5.5 & 6.1 & 0.5 \\
Cranial nerve deficits & 3 & 3 & 0.2 \\
Tracheostomy & 3 & 3 & 0.2 \\
\hline
\end{tabular}

The 12 patients included in the present study suffered from severe dysphagia persisting beyond four months after an acute brainstem lesion. 11 of them were initially fed by gastrostomy. After BT treatment 9 subjects (75\%) showed an improvement in the swallowing function and a reduction in the aspiration risk and in 7 cases it was possible to remove tube feeding $(63 \%)$. In literature, the effectiveness of BT injection and the duration of the effect was variable. Previous studies reported that after only one injection of BT 8 of the 23 patients obtained improved clinical and videofluoroscopic findings that lasted one year. However, it is difficult to establish a relationship between etiology and clinical aspect.

The present study noted that one single BT injection was able to solve dysphagia in 2 cases. It was observed that there was an optimal recovery after just one BT injection where there was only hyperactivity of the UES associated with a minimal deficit of the pharyngeal constrictor and clinically non-involved cranial nerves.

Studies reported that the majority of patients needed to be re-injected during the follow-up, while Kim found that the effect of BT treatment lasted 12 weeks post-injection [18].

In this study 7 patients needed to be re-injected during the follow up. It was found that where there was a onesided paresis of IX and X cranial nerve subsequent to a motoneuronal nucleus lesion, the recovery was incomeplete and the patients required repeated treatments. In these cases lesions were documented by denervation activity of the cricopharyngeal muscle and of the pharyngeal constrictor.

The administered dose of BT varied among studies from 14 to 100 units of Botox (Allergan, Irvine, California, USA) or from 120 to 750 units of Dysport (Ipsen, Paris, France). The dose injected with endoscopic tech-

Table 6. Studies reporting dysphagia treatments with BT after brainstem not progressive pathologies.

\begin{tabular}{|c|c|c|c|}
\hline Author, year cases, diagnosis & Doses and BT injection technique & Efficacy, outcome measure & Effect duration complicances \\
\hline $\begin{array}{l}\text { Haapaniemi, } 2001 \\
1 \text { brainstem stroke } \\
\text { (nasogastric feeding) }\end{array}$ & $\begin{array}{c}14 \text { U Botox, bilateral } \\
\text { injection guided by endoscopy, } \\
\text { general anaesthesia }\end{array}$ & $\begin{array}{l}\text { Patient was fully able to maintain } \\
\text { nutrition by mouth for } 10 \text { months. }\end{array}$ & $\begin{array}{l}\text { 2nd treatment after } 12 \text { months } \\
\text { No complicances }\end{array}$ \\
\hline $\begin{array}{c}\text { Chiu, } 2004 \\
1 \text { brainstem haemorrhage } \\
\text { (nasogastric feeding) }\end{array}$ & $\begin{array}{l}120 \text { U Dysport, bilateral injection, } \\
\text { general anaesthesia and } \\
\text { direct laryngoscope guidance }\end{array}$ & $\begin{array}{l}\text { Deglutition and nutrition remained } \\
\text { good one year after injection }\end{array}$ & No complicances \\
\hline $\begin{array}{c}\text { Masiero, } 2006 \\
\text { ponto-cerebellar haemorrhage }\end{array}$ & $25 \mathrm{U}$, unilateral, guided by EMG & $\begin{array}{l}\text { PEG and tracheostomy were removed. } \\
\text { Clinical, VFS and manometric features } \\
\text { show good outcome up to } 24 \text { month }\end{array}$ & No complicances \\
\hline $\begin{array}{c}\text { Kim, } 20068 \text { patients } \\
\text { (3 cerebellar, } 2 \text { pontine haemorrhage, } \\
3 \text { lateral medulla stroke) }\end{array}$ & $\begin{array}{l}100 \mathrm{U} \text { Botox } \\
\text { endoscopic guidance } \\
\text { bilateral injection }\end{array}$ & $\begin{array}{l}\text { Efficacy up to } 12 \text { weeks in } 6 \text { cases, not } \\
\text { efficacy in } 2 \text { cases. Worse results } \\
\text { in patients with bulbar stroke }\end{array}$ & No complicances \\
\hline $\begin{array}{c}\text { Lee } 20096 \text { cases } \\
\text { (4 lateral medulla and } 1 \text { medial pontine } \\
\text { stroke, } 1 \text { pontocerebellar neoplasia) }\end{array}$ & $\begin{array}{l}100 \mathrm{U} \text { Botox, } 750 \text { Dysport } \\
\text { EMG or endoscopic } \\
\text { guidance bilateral injection }\end{array}$ & Clinical and VFS improvements & $\begin{array}{l}\text { Follow up after } 15 \text { - } 25 \text { days } \\
\text { No complicances }\end{array}$ \\
\hline $\begin{array}{l}\text { Terrè, } 20086 \text { stroke in the posterior } \\
\text { circulation ( } 6 \text { month after stroke) }\end{array}$ & $\begin{array}{l}100 \text { U BT-A injection guided } \\
\text { by endoscopy, bilateral injection }\end{array}$ & Clinical, VFS and manometric feature & $\begin{array}{l}\text { One only treatment } \\
\text { No complicance }\end{array}$ \\
\hline
\end{tabular}


nique was higher than that injected percutaneously (Table 6).

Lee used $100 \mathrm{U}$ Botox or $750 \mathrm{U}$ Dysport to treat either side of the cricopharyngeal muscle using percutaneous technique with EMG guide, while Masiero injected $25 \mathrm{U}$ of BT into one side of the cricopharyngeal muscle.

In this study, a variable dose of 15 - 30 units of botulinum toxin type A was percutaneously injected into one or both side of the cricopharyngeal muscle under EMG control. At the first treatment, low doses were always administered, with a trend to increase them in the event of failure or with incomplete progress.

It seemed that there wasn't a relationship between the success rate and the administered dose on clinical grounds, although several authors discussed a probable dose-related benefit. In addition, the BT dosage used doesn't apparently affect the duration of BT effect [17]. Shaw and Searl suggested that a higher dosage could have resulted in a longer duration of effect [21]. Terrè proposed that just one BT injection was sufficient in patients selected with esophageal manometry [20].

The great variability of dosages in the different studies appeared to arise from the BT injection methods. In this study, no relationship was observed between duration of effect and dosage of BT used. The injection of BT guided by EMG allowed the use of very low doses because of less dispersion into the surrounding tissues. The treatment of both sides of the cricopharyngeal muscle improved the neuromuscular block and reduced the later diffusion of BT. In general, there were two main technical conditions required for success: injection in the horizontal part of the cricopharyngeal muscle and not into the caudal fibers of the inferior pharyngeal constrictor muscle, and exact injection into muscle fibers and not into fibrous tissue.

In previous studies, 4 patients failed to respond to BT injection. Terrè found that the 2 patients who did not respond had shown prior to treatment high UES residual pressure during swallowing in the manometric examination [20]. Kim proposed that a possible cause of ineffectiveness might have been the involvement of the bulbar swallowing centre [18]. Zaninotto indicated that a successful outcome was related to less severely damaged swallowing functions, as evaluated by VFSS and the presence of cricopharyngeal spasm at EMG [22].

In our study, 3 patients did not benefit from BT injection. It was observed that where there was a bilateral nuclear deficit with dysmotility and insufficiency of the pharyngeal constrictor, BT treatment gave poor outcomes.

This study employed the percutaneous technique with EMG guidance, which was less invasive, less difficult and faster than endoscopic injection and did not require general anesthesia. This technique was well tolerated without the occurrence of serious side effects. Other studies reported additional complications including: pharyngeal tears and transient palsy of the vocal cords [15,21], one case of urine retention [15] for which the anesthesia could be held responsible, and one "death through aspiration", which was attributed to the underlying disease [22].

\section{CONCLUSIONS}

In conclusion, in selected cases, BT injection allowed patients to re-establish the swallowing function and to resume oral feeding. Outcomes were better in dysphagic, even severe, subjects that did not show an important nuclear involvement of the IX and X cranial nerve with a consequent degeneration of the second motor neuron.

The clinical findings connected with the response to treatment were: failure of the veil-drooping, unilateral or bilateral paralysis of the constrictor of the pharynx and hyperactivity of the sphincter.

Accordingly, BT treatment gave best results in dysphagic patients with elective hyperactivity of the UES whether or not associated with unilateral paresis of the inferior constrictor muscle. On the other hand, outcome tended to be unsatisfactory in cases of oral phase involvement, bilateral lesion of the inferior constrictor muscle and when there was velopharyngeal insufficiency.

\section{REFERENCES}

[1] Bian, R.X., Choi, I.S., Kim, J.H., Han, J.Y. and Lee, S.G. (2009) Impaired opening of the upper esophageal sphincter in patients with medullary infarctions. Dysphagia, 24, 238-245. http://dx.doi.org/10.1007/s00455-008-9179-7

[2] Teasell, R., Foley, N., Doherty, T. and Finestone, H. (2002) Clinical characteristics of patients with brainstem strokes admitted to a rehabilitation unit. Archives of Physical Medicine and Rehabilitation, 83, 1013-1016. http://dx.doi.org/10.1053/apmr.2002.33102

[3] Aydogdu, I., Ertekin, C., Tarlaci, S., Turman, B., Kiylioglu, N. and Secil, Y (2001) Dysphagia in lateral medullary infarction (Wallenberg's syndrome): An acute disconnection syndrome in premotor neurons related to swallowing activity? Stroke, 32, 2081-2087. http://dx.doi.org/10.1161/hs0901.094278

[4] Kim, H., Chung, C.S., Lee, K.H. and Robbins, J. (2000) Aspiration subsequent to a pure medullary infarction: Lesion sites, clinical variables, and outcome. Archives of Neurology, 57, 478-483.

http://dx.doi.org/10.1001/archneur.57.4.478

[5] Horner, J., Buoyer, F.G., Alberts, M.J. and Helms, M.J. (1991) Dysphagia following brain-stem stroke. Clinical correlates and outcome. Archives of Neurology, 48, 11701173.

http://dx.doi.org/10.1001/archneur.1991.00530230078026

[6] Han, D.-S., Chang, Y.-C., Lu, C.-H. and Wang, T.-G. 
(2005) Comparison of disordered swallowing patterns in patients with recurrent cortical/subcortical stroke and first-time brainstem stroke. Journal of Rehabilitation Medicine, 37, 189-191.

[7] Schneider, I., Thumfart, W.F., Pototschnig, C. and Eckel, H.E. (1994) Treatment of dysfunction of the cricopharyngeal muscle with botulinum A toxin: Introduction of a new, noninvasive method. Annals of Otology, Rhinology, and Laryngology, 103, 31-35.

[8] Logemann, J.A., Veis, S. and Colangelo, L. (1999) A screening procedure for oropharyngeal dysphagia. Dysphagia, 14, 44-51. http://dx.doi.org/10.1007/PL00009583

[9] Daniels, S.K., Anderson, J.A. and Willson, P.C. (2012) Valid items for screening dysphagia risk in patients with stroke: A systematic review. Stroke, 43, 892-897. http://dx.doi.org/10.1161/STROKEAHA.111.640946

[10] Prosiegel, M., Heintze, M., Wagner-Sonntag, E., Hannig, C., Wuttge-Hannig, A. and Yassouridis, A. (2002) Deglutition disorders in neurological patients. A prospective study of diagnosis, pattern of impairment, therapy and outcome. Nervenarzt, 73, 364-370. http://dx.doi.org/10.1007/s00115-002-1284-5

[11] Rosenbek, J.C., Robbins, J.A., Roecker, E.B., Coyle, J.L. and Wood, J.L. (1996) A penetration-aspiration scale. Dysphagia, 11, 93-98. http://dx.doi.org/10.1007/BF00417897

[12] Santus, G., Faletti, S., Bordanzi, I., Pirali, F. and De Grandis, D. (2011) Effect of short-term electrical stimulation before and after botulinum toxin injection. Journal of Rehabilitation Medicine, 43, 420-423. http://dx.doi.org/10.2340/16501977-0790

[13] Marchese-Ragona, R., De Grandis, D., Restivo, D.A., Staffieri, A., Marioni, G. and Pastore, A. (2003) Recovery of swallowing disorders in patients undergoing supracricoid laryngectomy with botulinum toxin therapy. Annals of Otology, Rhinology, and Laryngology, 112, 258-263.

[14] Alfonsi, E., Merlo, I.M., Ponzio, M., Montomoli, C., Tassorelli, C., Biancardi, C., et al. (2010) An electrophysiological approach to the diagnosis of neurogenic dysphagia: Implications for botulinum toxin treatment. Journal of Neurology, Neurosurgery \& Psychiatry, 81, 54-60. http://dx.doi.org/10.1136/jnnp.2009.174698
[15] Haapaniemi, J.J., Laurikainen, E.A., Pulkkinen, J. and Marttila, R.J. (2001) Botulinum toxin in the treatment of cricopharyngeal dysphagia. Dysphagia, 16, 171-175. http://dx.doi.org/10.1007/s00455-001-0059-7

[16] Chiu, M.J., Chang, Y.C. and Hsiao, T.Y. (2004) Prolonged effect of botulinum toxin injection in the treatment of cricopharyngeal dysphagia: Case report and literature review. Dysphagia, 19, 52-57. http://dx.doi.org/10.1007/s00455-003-0029-3

[17] Masiero, S., Briani, C., Marchese-Ragona, R., Giacometti, P., Costantini, M. and Zaninotto, G (2006) Successful treatment of long-standing post-stroke dysphagia with botulinum toxin and rehabilitation. Journal of Rehabilitation Medicine, 38, 201-203. http://dx.doi.org/10.1080/16501970500515840

[18] Kim, D.Y., Park, C.I., Ohn, S.H., Moon, J.Y., Chang, W.H. and Park, S.W. (2006) Botulinum toxin type A for poststroke cricopharyngeal muscle dysfunction. Archives of Physical Medicine and Rehabilitation, 87, 1346-1351. http://dx.doi.org/10.1016/j.apmr.2006.06.018

[19] Lee, S.Y., Seo, H.G. and Paik, N.J. (2009) Botulinum toxin injection for dysphagia: A blinded retrospective videofluoroscopic swallowing study analysis. American Journal of Physical Medicine \& Rehabilitation, 88, 491494. http://dx.doi.org/10.1097/PHM.0b013e3181a0dc47

[20] Terre, R., Valles, M., Panades, A. and Mearin, F. (2008) Long-lasting effect of a single botulinum toxin injection in the treatment of oropharyngeal dysphagia secondary to upper esophageal sphincter dysfunction: A pilot study. Scandinavian Journal of Gastroenterology, 43, 12961303. http://dx.doi.org/10.1080/00365520802245403

[21] Shaw, G.Y. and Searl, J.P. (2001) Botulinum toxin treatment for cricopharyngeal dysfunction. Dysphagia, 16, 161-167. http://dx.doi.org/10.1007/s00455-001-0074-8

[22] Zaninotto, G., Marchese Ragona, R., Briani, C., Costantini, M., Rizzetto, C., Portale, G., et al. (2004) The role of botulinum toxin injection and upper esophageal sphincter myotomy in treating oropharyngeal dysphagia. Journal of Gastrointestinal Surgery, 8, 997-1006. http://dx.doi.org/10.1016/j.gassur.2004.09.037 